Advances in Geosciences, 3, 35-40, 2005

SRef-ID: $1680-7359 /$ adgeo/2005-3-35

European Geosciences Union

(c) 2005 Author(s). This work is licensed

under a Creative Commons License.

\title{
Space education in Kiruna, Northern Sweden
}

\author{
I. Sandahl ${ }^{*}, 1$ and A. Wikström ${ }^{1}$ \\ ${ }^{1}$ Dept. of Space Science, Kiruna, Luleå Univ. of Technology and Umeå University, Box 812, SE-981 28 Kiruna, Sweden \\ *now at: Swedish Institute of Space Physics, Box 812, SE-981 28 Kiruna, Sweden
}

Received: 30 September 2004 - Revised: 12 November 2004 - Accepted: 19 November 2004 - Published: 16 June 2005

\begin{abstract}
The town of Kiruna in the north of Sweden has a concentration of space activities and space research with, for example, the Swedish Institute of Space Physics, Esrange, the ESA Salmijärvi satellite station, and EISCAT (European Incoherent Scatter Radar) Scientific Association. The Department of Space Science is a joint department between the two most northern universities in Sweden, Luleå University of Technology and Umeå University in collaboration with the Swedish Institute of Space Physics. It offers a range of education programmes in the space field. There are bachelor and master programmes in space engineering, and a bridging programme for students without a science background from secondary school. The Department also contributes to courses for teachers, Ph.D. courses and secondary school level courses. One master's program and a three week summer course are given entirely in English and welcome international students. Thanks to good cooperation with Esrange students can build and fly experiments on high altitude balloons and sounding rockets and also take a large responsibility for the management of the projects. Close interaction with research and industry is an important part of the education.
\end{abstract}

\section{Introduction}

The town of Kiruna is a center of Swedish space research and space activities as well as a center of education in space physics and space technology. The government of Sweden has given a special directive to the Swedish Institute of Space Physics and to the two northernmost universities in Sweden, Luleå University of Technology and Umeå University, to work together to develop university education and research in space and environmental studies. This undertaking has been named Kiruna Space and Environment Campus (Sandahl and Norberg, 2003). For space education activities the

Correspondence to: I. Sandahl

(ingrid.sandahl@irf.se) two universities have formed a joint department in Kiruna, the Department of Space Science.

Kiruna is the northernmost town in Sweden, situated at 68 degrees north. The driving distance to Luleå is about $340 \mathrm{~km}$ and to Umeå about $600 \mathrm{~km}$. The respective locations are shown in the map in Fig. 1. Kiruna is a subarctic town and normally the ground is covered with snow from October until May. The popular tourist destination IceHotel in Jukkasjärvi is only $8 \mathrm{~km}$ from the Space Campus. Students and staff have an excellent chance to enjoy winter sport activities such as downhill and cross country skiing, wilderness tours, dog sledding, ice climbing and snow scooter rides. Sometimes reindeer herds graze in the forests around the Space Campus. Even though the Sun stays below the horizon for a period of 27 days in midwinter there are always several hours of light every day and in the summer the Midnight Sun shines from 30 May until 15 July. Kiruna owes its existence to the largest underground iron ore mine in the world, opened a century ago. Thanks to the mine, infrastructure was developed and scientists in different disciplines quickly took advantage of this possibility to have access to the northern environment. Space research started in 1957, the International Geophysical Year, when Kiruna Geophysical Observatory, KGO, was opened. Northernmost Sweden is in the auroral zone, and the possibility of studying the aurora and related magnetic disturbances was a strong reason for creating the observatory. Figure 2 shows auroral statistics obtained from the Allsky Camera in Kiruna. Aurora can be observed during most clear nights. It is now well known that the aurora is a visible manifestation of near-Earth space physics.

From a staff of five people at KGO in 1957 space activities in Kiruna have grown and today about 500 people work or study in the space sector. Since the total population of the municipality is about 23000 , this means that space constitutes a major factor both culturally and economically. KGO has developed into what is now the Swedish Institute of Space Physics, IRF, with research programs in Atmospheric Physics, Solar-Terrestrial Physics and Solar System Physics. Much of the research at IRF has a high technology level and 


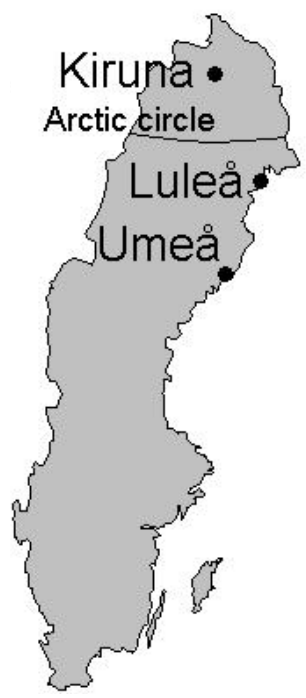

Fig. 1. Map of Sweden showing the locations of Kiruna, Luleå and Umeå.

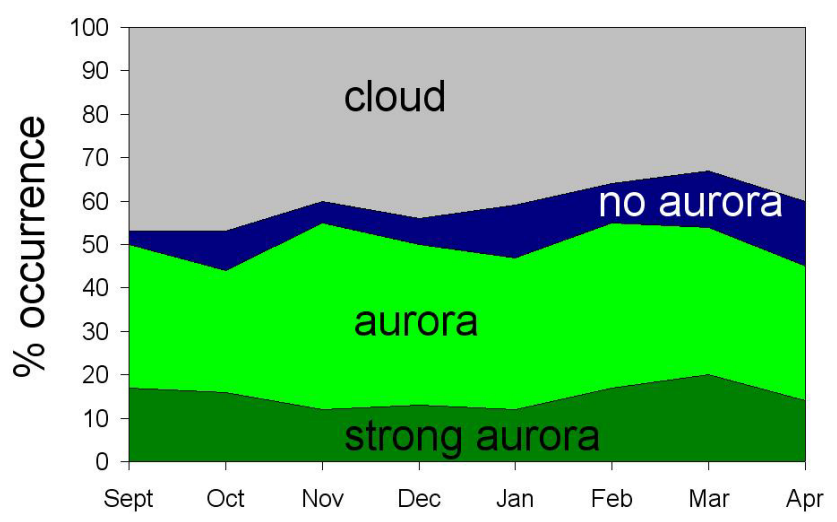

Fig. 2. Auroral statistics for Kiruna obtained from All-sky Camera data. Swedish Institute of Space Physics.

the institute is well known for its particle spectrometers such as the Mars Express ASPERA-3 instrument seen in Fig. 3. Esrange, Fig. 4, started as a sounding rocket and balloon launching range and has been an important satellite control and receiving station for many years, as well as a site for ground-based scientific instrumentation. Close to Esrange is the ESA Salmijärvi satellite station, Fig. 5, where data from Earth resource satellites such as ERS1 and Envisat are received. EISCAT (European Incoherent Scatter Radar) Scientific Association, an international organization operating three incoherent scatter radars in Northern Scandinavia, has its main office in Kiruna and one receiving station, Fig. 6, only $2 \mathrm{~km}$ from the Space Campus. At Kiruna airport is Arena Arctica, Fig. 7, a huge hangar designed and equipped for research aircraft used in atmospheric research. The rich space environment offers excellent possibilities for students to get contact with real space activities through, for example, study visits, visiting lecturers and student projects. This is one of the main reasons for the government decision to develop space education in Kiruna.

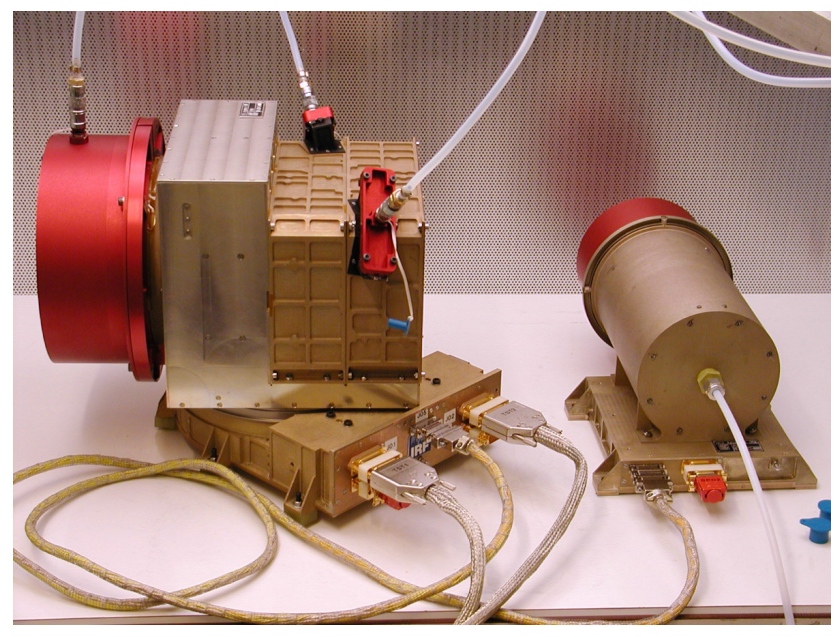

Fig. 3. Space activities in Kiruna began with what is now the Swedish Institute of Space Physics, IRF. Here the Mars Express ASPERA-3 particle instrument is shown.

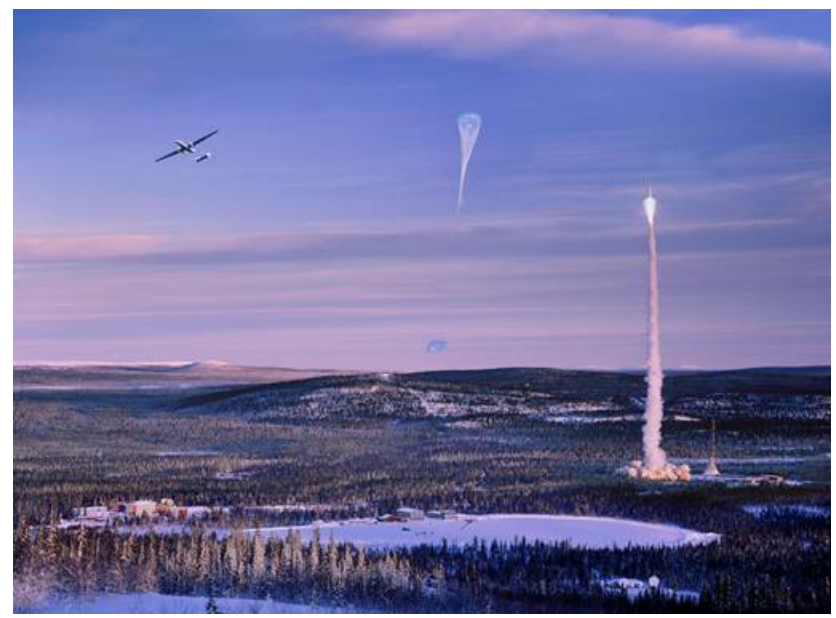

Fig. 4. Esrange is the largest space enterprise in Kiruna. Photo: Tomas Utsi, www.naturfoto.se

\section{Space education programs in Kiruna}

Space education activities are located at the Kiruna Space Campus in the same building as IRF. Kiruna Space Campus is situated in the forest $8 \mathrm{~km}$ east of the Kiruna center and $2 \mathrm{~km}$ from Kiruna airport. Figure 8 shows the Space Campus building. The wing to the right houses the Department of Space Science. In the middle is IRF. The round building to the left contains a restaurant, a library and an auditorium that are all used by both scientists and students. Thus students here have plenty of opportunities to meet active scientists.

Table 1 gives an overview of space education programmes in Kiruna. All of these programmes are given entirely in Kiruna except for the 4.5 year M.Sc. programme in which students spend most of the first three years in Luleå and move to Kiruna at the beginning of the fourth year. The Summer Course and the one-year M.Sc. programme are given in 


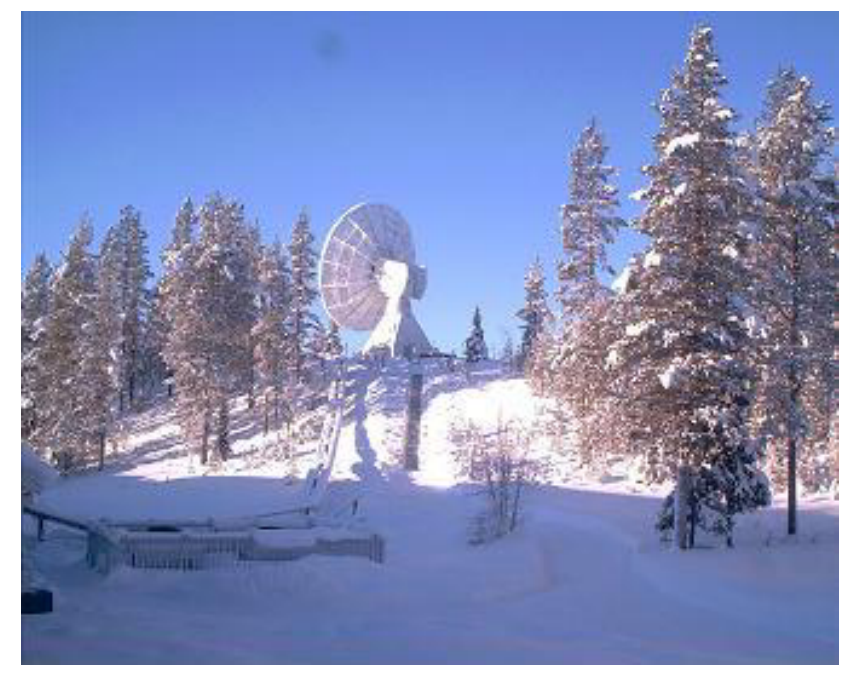

Fig. 5. The ESA Salmijärvi satellite station.

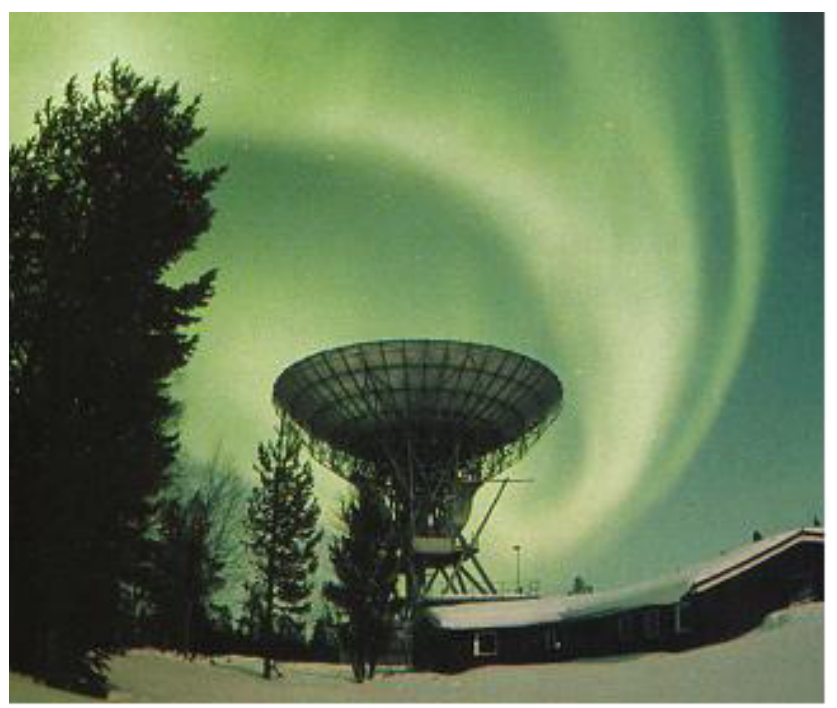

Fig. 6. The EISCAT receiving station in Kiruna. Photo: Torbjörn Lövgren

English and are described in special sections below. Doctoral students can also carry out their studies in English. For the other programmes students are required to know Swedish.

The Basic Technical education with Space Profile is a bridging programme for students who do not have enough background from secondary school to be eligible to study engineering, physics and similar subjects at university level. In this new programme space is used as a teaching vehicle, taking advantage of the fact that people in general find space and space applications fascinating and exciting. Subjects like mathematics and physics are put into a space context as much as possible and this should make learning more interesting, effective and enjoyable.

The B.Sc. programme in Space Engineering is strongly space-oriented right from the start. Much emphasis is put on the ability to solve practical engineering problems, to under-

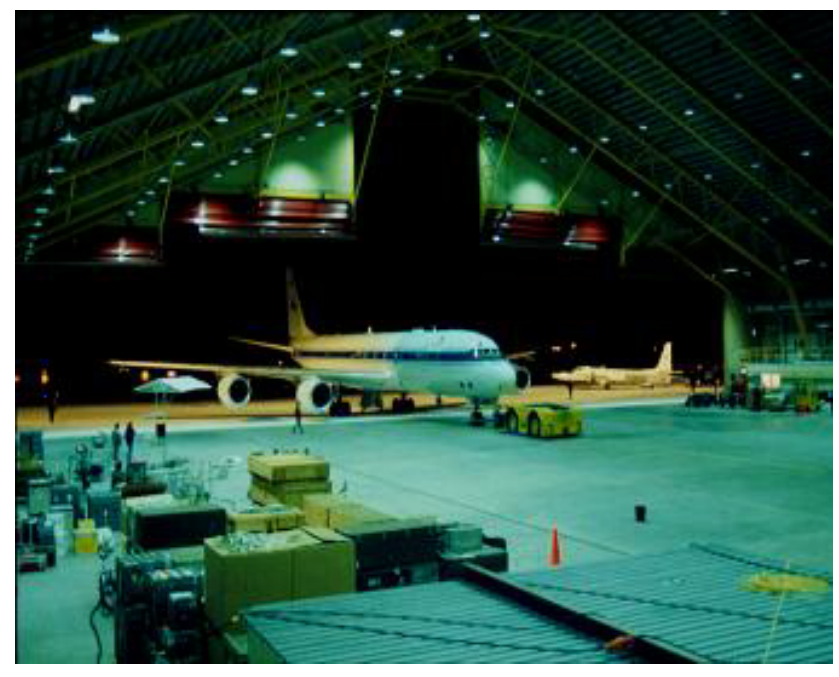

Fig. 7. Arena Arctica with the NASA research DC-8 and ER-2.

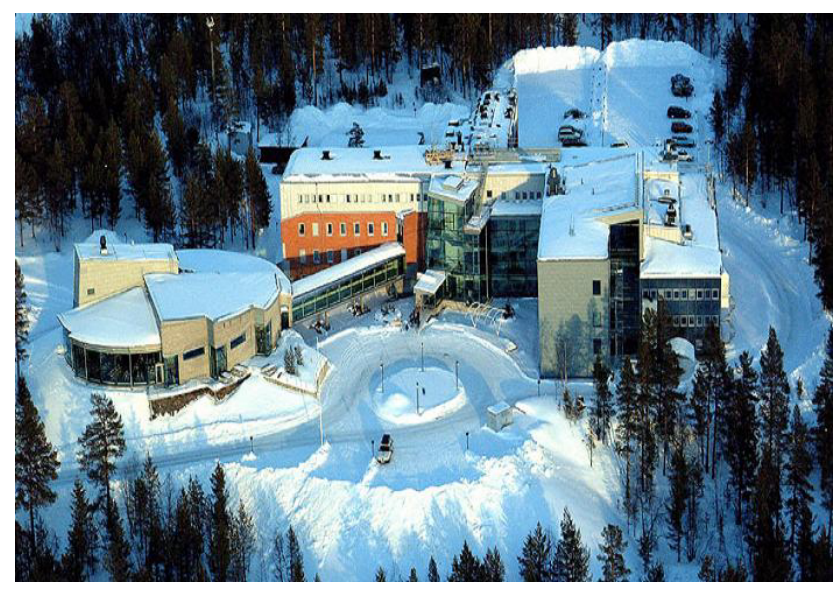

Fig. 8. The Kiruna Space Campus houses both the Swedish Institute of Space Physics and the Department of Space Science. Photo: T. Lövgren, Swedish Institute of Space Physics.

stand whole systems and to work on projects. Many of the B.Sc. students continue in the one year M.Sc. programme. The 4.5 year M.Sc. programme is more theoretical and in many ways similar to an Engineering Physics programme.

Ph.D. studies in space subjects have a longer history than all other types of space education in Kiruna. Between 1962 and 1972 physicists working in Kiruna obtained Ph.D.s from the University of Uppsala, but when the Umeå University was founded in 1965 doctoral degrees in Kiruna were eventually granted by that university. Today doctoral students in Kiruna are enrolled at Umeå University or Luleå University of Technology and it is possible to study for degrees in Space Physics, Space Technology and Atmospheric Physics. Many of the students belong to the National Graduate School in Space Technology (Eliasson et al., 2003), which is centered in Kiruna with Luleå University of Technology as host university. 
Table 1. Space education programs at the Department of Space Science. $\mathrm{LTU}=$ Luleå University of Technology, UmU = Umeå University

\begin{tabular}{ll}
\hline Programme/course & Given by \\
\hline Basic Technical Education with Space Pro- & UmU \\
file, 1 year & \\
Summer course, 3 weeks (in English) & UmU \\
$\begin{array}{l}\text { B.Sc. in Space Engineering, 3 years } \\
\text { Swedish M.Sc. in Space Engineering, 1- }\end{array}$ & UmU \\
$\begin{array}{l}\text { 1.5 year (in English) } \\
\text { M.Sc. in Space Engineering, 4.5 years }\end{array}$ & LTU \\
$\begin{array}{l}\text { Ph.D. in Space Physics, Space Technology } \\
\text { and Atmospheric Physics }\end{array}$ & UmU and LTU \\
Graduate school, Space Technology & LTU \\
\hline
\end{tabular}

In addition to the programmes and courses included in Table 1 there is also a privately operated space secondary school, years 10-12 in the Swedish school system. This school offers a natural science programme with a strong space profile and has students from all over Sweden. Some of its courses are given by the Department of Space Science. Finally, Kiruna is an affiliate campus of the International Space University.

During the study year 2003/2004 a total of nearly 150 students and 60 pupils studied at the Kiruna Space Campus. Among these 14 were Ph.D. students. The Summer Course had 12 and the one year M.Sc. programme 17 students. The foreign students came from Cameroon, Great Britain, India, Japan, Kenya, Pakistan, and Russia.

\subsection{Swedish Master of Science in Space Engineering}

In this programme students with a B.Sc. in physics, electronics or space engineering can earn a Swedish Master of Science degree in Space Engineering. No knowledge of Swedish is needed to follow the programme but good knowledge of English is required and students from all over the world can be accepted. The time needed to complete the degree depends on the background of each student and is assessed individually.

The curriculum is shown in Table 2. The study year begins at the end of August and ends in the beginning of June. It is divided into four study periods of 10 weeks each. During each study period there are a number of courses to choose between. Two courses at the time is considered a full-time work load for a student. Most courses give 5 Swedish study points, some give 10 . One point corresponds to one week of full-time work and one year of study to 40 points. Normally the minimum course work needed to obtain the degree is 25 points and in addition students must complete a degree project of 15 points. The degree project can be carried out at a university or a company anywhere in the world as long as quality is not compromised.

Students wishing to take just one or a few of the courses can be accepted, provided that there is still room.
Table 2. Courses offered in the Swedish M.Sc. in Space Engineering. ECTS is the European Credits Transfer System

\begin{tabular}{lll}
\hline Course name & points & ECTS \\
\hline Space environment & 5 & 7.5 \\
Real time systems in space & 5 & 7.5 \\
Sensors and Instruments & 5 & 7.5 \\
The Observational platform & 5 & 7.5 \\
Electronics in space & 5 & 7.5 \\
Electronics design with VHDL & 5 & 7.5 \\
Satellite techniques & 10 & 15 \\
Radar techniques & 5 & 7.5 \\
Space technology project & 5 or 10 & 7.5 or 15 \\
\hline
\end{tabular}

At present there is no tuition fee for foreign students in Sweden. Students have to pay for housing and other living expenses and for transportation.

\subsection{BEXUS - Balloon Experiment for University Students}

Thanks to excellent collaboration with Esrange space students in Kiruna have the chance to participate in a full scale balloon project, BEXUS - Balloon Experiment for University Students. The participation is organized in a set of project courses at different levels that students can choose. In order to give students the best possible training the project is, as much as possible, run as a "real" space project and the students are given significant technical and project management responsibility. Information about BEXUS in Swedish and English is found in the BEXUS home page http://www. krm.se/bexus/.

The BEXUS II project was carried out during the study year 2003/2004. The work began with issuing an Announcement of Opportunity (AO) to the students. The students then had to form project teams and write proposals for experiments. Students were expected to use their creativity and knowledge from earlier courses to come up with an interesting experiment, either a technological test or a scientific experiment. The AO had different levels for different student categories. Students from the two secondary schools in Kiruna were also invited to submit proposals, but their proposals had to be for experiments that did not require telemetry during flight.

A committee consisting of teachers and students selected the payload. Not all experiments could be accommodated, so the experiment teams had to be reorganized to some extent. During the hardware phase each team was given a budget and had to divide tasks and make sure that the experiment construction met the deadline. As the delivery date approached students could be found working in the labs almost around the clock to ensure delivery. Figure 9 shows a student working on the BEXUS platform.

In total more than 40 students and about 30 pupils participated in BEXUS. Here only a few examples of team projects are given: 
- Project management.

- The BEXUS platform. Platform electronics and ground station.

- BEXUS Active Stabilizer System, BASS, an instrument platform compensating for the movements of the balloon gondola. During the flight it was used for a digital camera.

- SSETI/Narrow Angle Camera, NAC. The camera is being designed for the ESA European Student Earth Orbiter, ESEO, and was tested on the balloon flight.

- Secondary school experiments. For example, tests of how various objects were affected by the cold and radiation during the flight. Among the tested objects were exposed and unexposed film, a raw and a boiled egg, mold on a piece of bread.

The successful flight of BEXUS took place on 26 February 2004 from Esrange (Fig. 10). Before the flight the students carried out payload checkout and during the flight the performance was monitored. The balloon flew east over Finland reaching a maximum altitude of $27600 \mathrm{~m}$. All experiments worked well. The payload was recovered by helicopter.

The final phase of the course was to analyze the data and write reports. The results were presented in a press conference. The press was also invited to be present at the launch.

Student evaluations of the course were enthusiastic. Many students rated this as the best course they had ever taken and one student claimed that she had learned more from BEXUS than from all theoretical courses combined.

There is now an agreement with Esrange to fly one BEXUS balloon per year. This makes it possible to integrate BEXUS related material into many of the courses offered in Kiruna.

\subsection{REXUS - Student rocket}

As a result of a collaboration between Esrange and DLR (Deutschen Zentrum für Luft- und Raumfahrt or German Aerospace Center) students have also been given an opportunity to fly experiments on a sounding rocket. The rocket is an Improved Orion and apogee is at $110 \mathrm{~km}$. The REXUS project is being run in much the same way as BEXUS. The student payload has a mass of $7 \mathrm{~kg}$. Launch is planned for October 2004.

\subsection{Summer course in Space Science and Technology}

Since 2003 students with at least one year of university background have had the opportunity to take the introductory course Space Science and Technology in the Land of the Midnight Sun. This is an intensive course of 5 points or 7.5 ECTS (European Credit Transfer System), taking place during 3 weeks in August. Topics covered are mechanics, gravitation, atmospheric physics, space physics, space instruments and space electronics. Study visits are made to IRF,

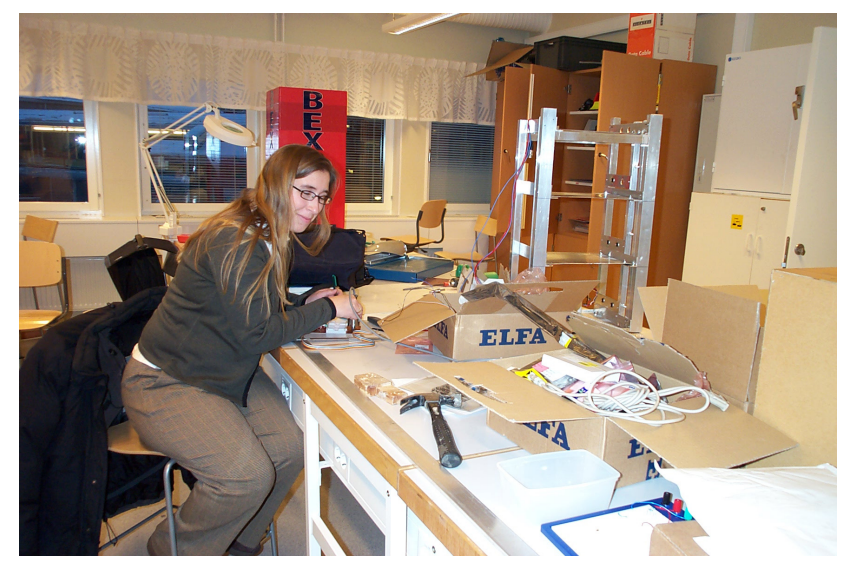

Fig. 9. A student at work on the BEXUS platform.

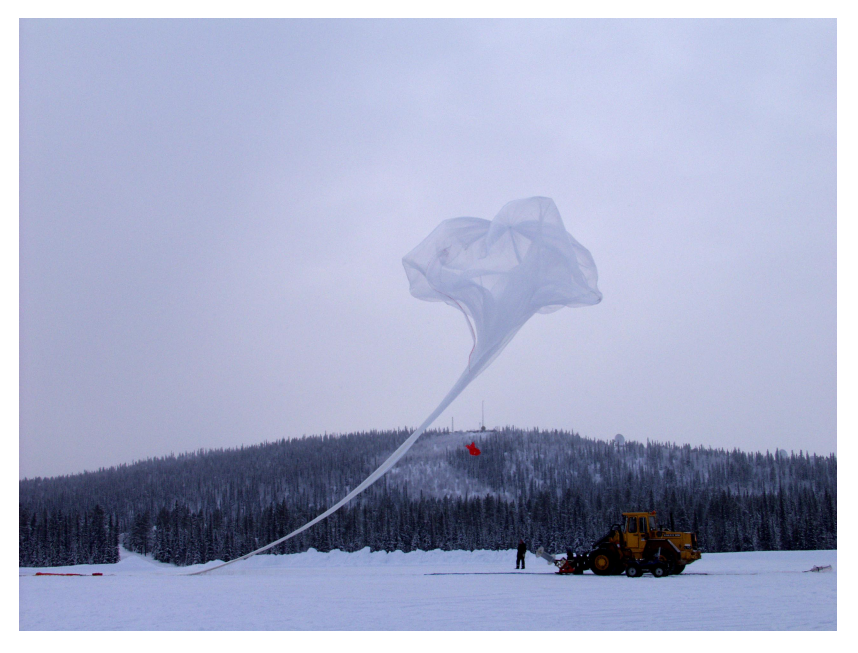

Fig. 10. The BEXUS II student project balloon, launched from Esrange in February 2004.

Esrange and the EISCAT receiving station. The entire course is given in English and so far students from 5 countries have participated. No tuition fee is charged.

A popular part of the course is the rocket laboratory. The students build their own model rockets (Fig. 11). They test stability and calculate the maximum altitude. The rockets are then launched at Esrange (Figs. 12 and 13) and performance is compared to calculations.

\section{Plan for international M.Sc.}

Work is now in progress to create a two year international M.Sc. programme in Space Technology in agreement with the Bologna declaration. This programme will be launched as soon as the necessary decisions have been taken by the Swedish government, probably from the Autumn semester 2006. The Bologna process is an important and wide ranging reform of higher education in Europe. The ultimate aim is to establish a European Higher Education Area by 2010 in which staff and students can move easily between different 


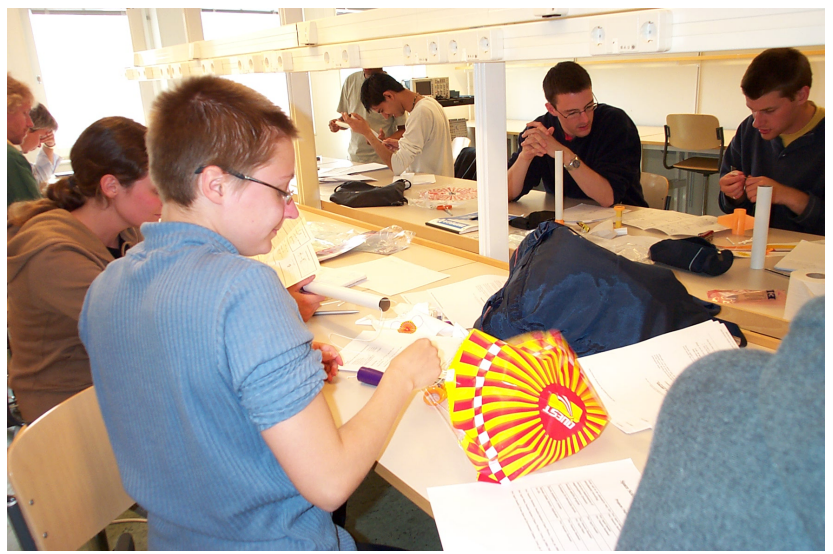

Fig. 11. Summer students building model rockets.

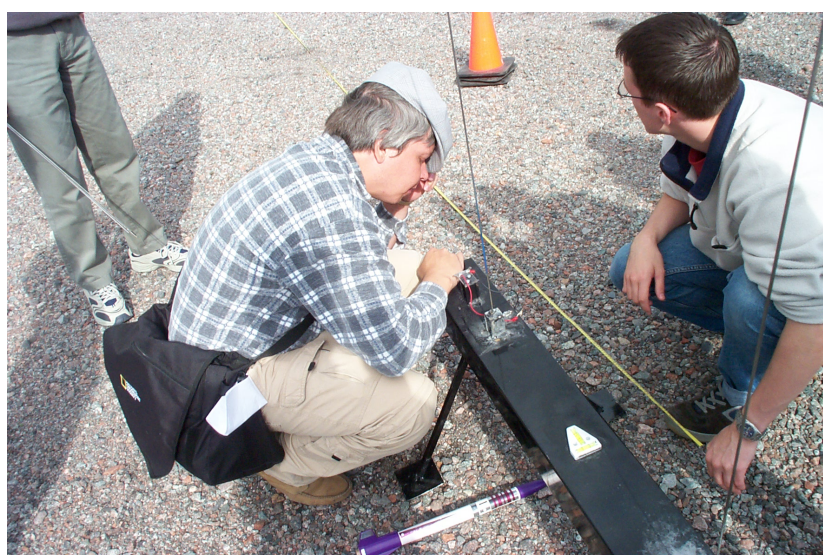

Fig. 12. Setting up the launcher.

countries and have fair recognition of their qualifications. The declaration was signed in 1999 by the European ministers of education. The Bologna system is based in two main cycles, an undergraduate of at least three years and a graduate leading to a master and/or doctorate degree.

\section{Conclusions}

Kiruna offers unique possibilities for students at different levels to study space related subjects in close interaction with research and industry. Hands on experiences are an important part of the education. More information can be found at http://www.ltu-umu.irv.se.

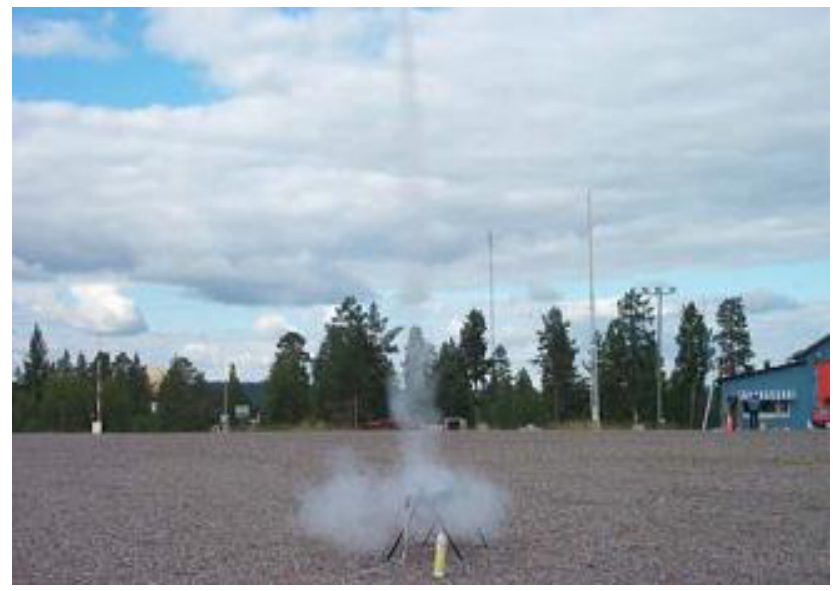

Fig. 13. Model rocket launch campaign. Blastoff.

Acknowledgements. We wish to thank The Swedish Space Corporation, Esrange division, and DLR for making the projects BEXUS and REXUS possible. We are very thankful for the excellent spirit of collaboration within the space sector in Kiruna. We thank both referees for useful comments.

\section{Edited by: N. Crosby}

Reviewed by: C. Welch and L. Chambers

\section{References}

Sandahl, I. and Norberg, C.: Space education at Kiruna Space and Environment Campus, Proceedings of the 16th Symposium on European Rocket and Balloon Programmes and Related Research, St. Gallen, Switzerland, 2-5 June 2003, ESA SP-530, 75-77, 2003.

Eliasson, L., Sandahl, I., and Norberg, O.: Swedish National Graduate School of Space Technology, Proceedings of the 16th Symposium on European Rocket and Balloon Programmes and Related Research, St. Gallen, Switzerland, 2-5 June 2003, ESA SP-530, 71-74, 2003. 